\title{
APLICABILIDADE DE UMA MICRO USINA FOTOVOLTAICA DE GERAÇÃO DE ENERGIA ELÉTRICA CONECTADA À REDE E SUAS INTERAÇÕES
}

\author{
Italo Alves Montorio Junior ${ }^{1}$,, Tadeu Alcides Marques², Alba Regina Azevedo Arana² \\ ${ }^{1}$ Instituto Federal de Educação Ciência e Tenologia de São Paulo - IFSP, Câmpus Presidente Epitácio, Área Indústria, \\ Presidente Epitácio, SP. \\ ${ }^{2}$ Universidade do Oeste Paulista - UNOESTE, Mestrado Meio Ambiente e Desenvolvimento Regional, Presidente \\ Prudente, SP. E-mail: italo.ifsp@gmail.com.
}

\section{RESUMO}

A energia da luz solar influencia os movimentos dos ventos, os ciclos da água, a fotossíntese das plantas, a existência dos combustíveis fósseis e a existência e a manutenção da vida na Terra. A luz solar é a fonte primária de toda a energia do planeta. É abundante, disponível, inesgotável, não poluente e distribuída por toda a superfície terrestre. Uma das infinitas formas de utilização é a geração de energia elétrica. A pesquisa tem como objetivo estudar a aplicabilidade de uma micro usina fotovoltaica conectada à rede elétrica e as vantagens da geração distribuída. A metodologia recaiu na pesquisa básica e documental que constou em compilar os dados de geração e de consumo de uma unidade consumidora. Os resultados foram apresentados em planilhas e gráficos e mostraram a integração da micro usina ao sistema de fornecimento de energia elétrica. Concluise que o modelo é tecnicamente viável.

Palavras-chave: energia, solar, geração, distribuída, usina.

\section{APPLICABILITY OF A MICRO PHOTOVOLTAIC POWER ELECTRICAL GENERATION CONNECTED TO THE NETWORK AND ITS INTERACTIONS}

\begin{abstract}
Sunlight energy influences wind movements, water cycles, photosynthesis of plants, the existence of fossil fuels, and the existence and maintenance of life on Earth. Sunlight is the primary source of all the planet's energy. It is abundant, available, inexhaustible, non-polluting and distributed throughout the earth's surface. One of the infinite forms of use is the generation of electric energy. The research aims to study the applicability of a photovoltaic micro power plant connected to the grid and the advantages of distributed generation. The methodology fell on the basic and documental research that consisted in compiling the data of generation and consumption of a consumer unit. The results were presented in spreadsheets and graphs and showed the integration of the micro power plant to the electric power supply system. We conclude that the model is technically feasible.
\end{abstract}

Keywords: energy, solar, generation, distributed, power plant. 


\section{INTRODUÇÃO}

Duas entidades constituem o Universo: a matéria e a energia, sendo a matéria definida como aquilo que torna a existência do meio ambiente físico e biológico viável e a energia como a capacidade que matérias ou sistemas físicos têm em realizar trabalho.

Segundo a primeira lei da termodinâmica, num sistema isolado, nenhuma energia pode ser criada ou destruída, porém pode se transformar de uma forma para outra de modo que a quantidade total de energia é sempre constante. Por este motivo esta lei também é conhecida como a lei da conservação da energia. (BOTKIN E KELLER, 2011).

Já a segunda lei da termodinâmica garante que, quando há transformação da energia de uma forma para outra, essa sempre caminha da forma mais proveitosa para outra menos proveitosa. (BOTKIN E KELLER, 2011).

Albert Einstein descreveu a equivalência entre matéria e energia por meio da seguinte relação: $E=m c^{2}$ ( $m=$ massa; $c=$ velocidade da luz no vácuo= $300.000 \mathrm{~km} / \mathrm{s}$ ). Assim ficou evidente que estas duas entidades são intercambiáveis (VIEIRA et al., 2004).

Durante a sua evolução, a espécie humana sempre procurou modificar o seu habitat de modo a oferecer melhores condições de subsistência. Para tanto, se fez necessário o controle dos eventos naturais lesivos à vida e ao desenvolvimento, como: frio, calor, ausência de luz, produção e conservação de alimentos, grandes distâncias, proteção, dentre outros. Estes eventos bem como o domínio deles estão relacionados à matéria, à energia e às suas transformações.

O controle do fogo foi o primeiro grande avanço no uso da energia. Os primeiros combustíveis a serem utilizados para alimentar o fogo e para produzir energia foram madeiras e seus derivados. Com o esgotamento das florestas europeias, devido ao uso intensivo sem a devida reposição, esses combustíveis foram substituídos por outros, como o coque, os derivados da hulha e o carvão betuminoso. (CARVALHO, 2014).

A invenção da máquina a vapor no século XVIII foi o grande marco da utilização da energia pelo homem e deu início à era da Revolução Industrial na Europa. Na busca pelo aprimoramento das máquinas utilizadas nas indústrias para confecção de produtos, teve início, na metade do século XIX, o uso intensivo de novas fontes de energia, notadamente o petróleo e a eletricidade. (LOPEZ, 2012).

A humanidade passou, então, por um crescimento econômico e populacional nunca visto antes na história do planeta. Apesar de todo este crescimento, o meio ambiente bem como a população em geral têm sofrido diversas agressões, às vezes irreversíveis. Aumento do efeito estufa, diminuição da camada de ozônio e poluição atmosférica são algumas das consequências danosas provocadas pelo uso indiscriminado de fontes energéticas poluidoras. Apesar de várias fontes alternativas estarem sendo propostas, a mudança de comportamento ainda é muito lenta e depende de fatores econômicos, de interesses individuais e de quebra de reservas de mercados. A produção de energia elétrica tem grande participação nestas alterações. Diversas fontes são utilizadas na geração, muitas delas são não renováveis e poluidoras. (REIS, 2003).

A Tabela 1, cujos dados foram extraídos do Balanço Energético Nacional 2016 elaborado pela Empresa de Pesquisas Energéticas (EPE) e adaptados pelos autores, mostra a participação das diversas fontes utilizadas para a produção de energia elétrica no período de 2011 a 2015, bem como a participação em porcentagem (\%) e a variação entre os anos de 2014 e de 2015 de cada fonte na matriz elétrica brasileira.

Das fontes utilizadas para geração, a hidráulica é a que possui maior participação na matriz elétrica brasileira. É uma fonte renovável. Para Fearnside (2015), apesar de ser considerada limpa, causa grandes impactos ambientais na construção e emite gás Metano $\left(\mathrm{CH}_{4}\right)$ na decomposição da matéria orgânica. Embora as condições naturais sejam favoráveis no Brasil, a hidráulica é uma fonte vulnerável às crises hídricas, provocadas pela falta de chuvas, sendo necessário utilizar as termoelétricas para suprir as necessidades de consumo, cuja energia gerada é mais cara, além de 
produzirem muitos poluentes que são lançados ao meio ambiente. As termoelétricas utilizam o Gás Natural, o Carvão Mineral, os derivados de Petróleo, o Urânio nas usinas nucleares e a biomassa como fontes para a geração, sendo a biomassa a única fonte renovável. A energia dos ventos, fortes e constantes em grande parte do país, é considerada uma fonte renovável, limpa e de baixo custo operacional e de implantação. Sua participação vem crescendo nos últimos anos, porém ainda contribui pouco na matriz.

Tabela 1. Geração elétrica anual por fonte na matriz elétrica brasileira (GWh)

\begin{tabular}{|l|r|r|r|r|r|c|c|}
\hline \multicolumn{1}{|c|}{ FONTES / ANO } & $\mathbf{2 0 1 1}$ & $\mathbf{2 0 1 2}$ & $\mathbf{2 0 1 3}$ & $\mathbf{2 0 1 4}$ & $\mathbf{2 0 1 5}$ & $\begin{array}{c}\text { Part. \% } \\
\mathbf{( 2 0 1 5 )}\end{array}$ & $\begin{array}{c}\Delta \% \\
\mathbf{( 2 0 1 5 / 2 0 1 4 )}\end{array}$ \\
\hline Total & $\mathbf{5 3 1 . 7 5 8}$ & $\mathbf{5 5 2 . 4 9 8}$ & $\mathbf{5 7 0 . 8 3 5}$ & $\mathbf{5 9 0 . 5 4 2}$ & $\mathbf{5 8 1 . 4 8 6}$ & $\mathbf{1 0 0 , 0 \%}$ & $\mathbf{- 1 , 5 \%}$ \\
\hline Gás Natural & 25.095 & 46.760 & 69.003 & 81.073 & 79.490 & $13,7 \%$ & $-2,0 \%$ \\
\hline Derivados de Petróleo (i) & 12.238 & 16.214 & 22.090 & 31.529 & 25.662 & $4,4 \%$ & $-18,6 \%$ \\
\hline Carvão mineral & 6.485 & 8.422 & 14.801 & 18.385 & 19.096 & $3,3 \%$ & $3,9 \%$ \\
\hline Nuclear & 15.659 & 16.038 & 15.450 & 15.378 & 14.734 & $2,5 \%$ & $-4,2 \%$ \\
\hline Hidráulica (ii) & 428.333 & 415.342 & 390.992 & 373.439 & 359.743 & $61,9 \%$ & $-3,7 \%$ \\
\hline Biomassa (iii) & 31.633 & 34.662 & 39.679 & 44.987 & 47.394 & $8,2 \%$ & $5,4 \%$ \\
\hline Eólica & 2.705 & 5.050 & 6.578 & 12.210 & 21.626 & $3,7 \%$ & $77,1 \%$ \\
\hline Solar & 0 & 2 & 5 & 16 & 59 & $0,0 \%$ & $268,8 \%$ \\
\hline Outras (iv) & 9.609 & 10.008 & 12.237 & 13.524 & 13.682 & $2,4 \%$ & $1,2 \%$ \\
\hline
\end{tabular}

Organização: Autor

Notas: i) Derivados de Petróleo: óleo diesel e óleo combustível; ii) Inclui auto produção;

iii) Biomassa: lenha, bagaço de cana e lixívia; iv) Outras: recuperações, gás de coqueria e outros secundários.

Outra fonte que vem sendo utilizada para geração de energia elétrica é a da luz solar. Apesar de contribuir muito pouco na matriz energética brasileira, a sua participação cresceu 268,8\% em 2015 quando comparados aos valores de 2014. O sol é a fonte primária de toda a energia do planeta. É abundante, disponível, inesgotável, não poluente e distribuída por toda a superfície terrestre. A energia da luz solar influencia os movimentos dos ventos, os ciclos da água, a fotossíntese das plantas, a existência dos combustíveis fósseis e a existência e a manutenção da vida na Terra.

As usinas Hidroelétricas aproveitam a energia potencial que as águas possuem quando estão nos pontos mais altos. Ao escorrerem para as partes mais baixas por meio da força gravitacional, esta energia potencial é transformada em energia cinética. Nas turbinas é convertida em energia mecânica e nos geradores, em elétrica. Por meio do ciclo hidrológico do planeta, onde o sol cumpre papel fundamental ao promover a evaporação, a água volta para as partes mais altas, reiniciando o ciclo.

O Gás Natural, o Carvão Mineral e o Petróleo são combustíveis fósseis oriundos de decomposições anaeróbicas de matérias orgânicas ocorridas há milhares de anos. Em algum momento houve a influencia do sol na produção vegetal. "Se os combustíveis têm origem em seres vivos e se os seres vivos obtêm energia da luz solar, por meio da fotossíntese, então, toda a energia existente nos combustíveis é proveniente do Sol." (LOPEZ, 2012, p. 20). Esta energia ficou armazenada nestes combustíveis até o seu uso. As vegetações que formam as biomassas também 
necessitam da energia da luz solar para se desenvolverem. As correntes eólicas são formadas a partir das diferenças de temperatura e de pressão do planeta influenciadas pela energia solar.

A pesquisa tem como objetivo apresentar a aplicabilidade de uma micro usina fotovoltaica (MUF) conectada à rede elétrica utilizando a luz solar como fonte primária e as vantagens da geração distribuída. Neste modelo a produção ocorre no próprio local de utilização da energia o que evita as perdas por efeito joule no sistema de condução, diminui os custos com energia elétrica dos consumidores e contribui para diminuição do uso de usinas termoelétricas.

\section{METODOLOGIA}

Os dados de consumo de energia elétrica apresentados neste estudo foram obtidos por meio de leitura do padrão de medição da concessionária, instalado na entrada de fornecimento de energia ao Instituto Federal São Paulo (IFSP) Câmpus Presidente Epitácio $\left(21,786^{\circ} \mathrm{S} ; 52,112^{\circ} \mathrm{W}\right.$ ), situado no município de Presidente Epitácio, estado de São Paulo, disponibilizados na página eletrônica da ENERGISA (2017). Esta unidade consumidora pertence ao grupo A, segundo classificação da Agencia Agência Nacional de Energia Elétrica (Aneel) e recebe energia em alta tensão (13.800V). Possui um transformador de 225 KVA e uma demanda contratada de 128 KW. Os gráficos e os dados de geração de energia elétrica foram obtidos de uma micro usina fotovoltaica instalada neste instituto, conectada à rede de distribuição de energia elétrica da concessionária CAIUÁ S/A, disponibilizados na página eletrônica da FRONIUS (2017). A micro usina é composta por 36 placas monocristalinas de $265 \mathrm{Wp}$ com dimensão de 1,65 $\mathrm{m}^{2}$, totalizando 9,54 $\mathrm{KWp}$ e uma área útil de $59,40 \mathrm{~m}^{2}$. As placas foram dispostas de modo a formar uma cobertura para automóveis com orientação de $40^{\circ} \mathrm{NW}$ e com inclinação de $22^{\circ}$.

A Análise dos resultados foi feita com base nos dados e gráficos obtidos e confeccionados, compilando-os em planilhas eletrônicas. Foram analisados o consumo e a geração de energia elétrica dos meses de junho a setembro de 2017.

\section{RESULTADOS}

A Tabela 2 apresenta a energia registrada pela concessionária, a gerada pela micro usina fotovoltaica, a enviada para a concessionária e a energia total utilizada pela instituição, em KWh. Nos momentos em que há grande incidência de luz solar e a energia utilizada pelas cargas instaladas no Instituto é menor que a energia gerada pela micro usina, ocorre o envio do excedente para o sistema.

Como a micro usina fotovoltaica (MUF) possui capacidade de geração pequena em relação ao consumo da instituição, o excedente ocorre somente nos finais de semana e nos feriados, quando não ocorrem atividades na instituição.

Tabela 2. Levantamento da energia consumida e da gerada por mês na instituição

\begin{tabular}{|c|c|c|c|c|c|}
\hline \multirow[t]{2}{*}{ MÊS } & $\begin{array}{l}\text { EE fornecida pela } \\
\text { concessionária }\end{array}$ & $\begin{array}{l}\text { EE gerada } \\
\text { pela MUF }\end{array}$ & $\begin{array}{c}\text { EE } \\
\text { injetada } \\
\text { na rede }\end{array}$ & $\begin{array}{l}\text { EE total } \\
\text { utilizada }\end{array}$ & $\begin{array}{c}\text { Relação entre } \\
\text { energia gerada / } \\
\text { utilizada }\end{array}$ \\
\hline & (kWh) & (kWh) & (kWh) & (kWh) & (\%) \\
\hline jun/17 & $11.377,04$ & $1.049,29$ & 10,33 & $12.416,00$ & $8,45 \%$ \\
\hline jul/17 & $6.507,43$ & $1.177,54$ & 40,03 & $7.644,94$ & $15,40 \%$ \\
\hline ago/17 & $15.336,50$ & $1.123,95$ & 31,08 & $16.429,37$ & $6,84 \%$ \\
\hline set/17 & $21.292,46$ & $1.358,64$ & 26,39 & $22.624,71$ & $6,01 \%$ \\
\hline média & $13.628,36$ & $1.177,36$ & 26,96 & $14.778,76$ & $9,18 \%$ \\
\hline
\end{tabular}


Os Gráficos 1, 2 e 3 mostram, respectivamente, a geração, o consumo e a energia entregue ao sistema no dia 23 de julho de 2017, domingo. Como não houve atividades na instituição, somente as cargas essenciais estavam energizadas. Pelo Gráfico 1 nota-se que foi um dia de sol pleno, o que proporcionou geração contínua. No Gráfico 2 observa-se que a curva de consumo é inversa ao de geração, comprovando que a energia consumida pelas cargas estavam sendo fornecidas pela micro usina fotovoltaica. Já o Gráfico 3 traz a energia que foi gerada a mais do que a consumida e foi exportada para o sistema.

Gráfico 1. Energia gerada pela micro usina fotovoltaica

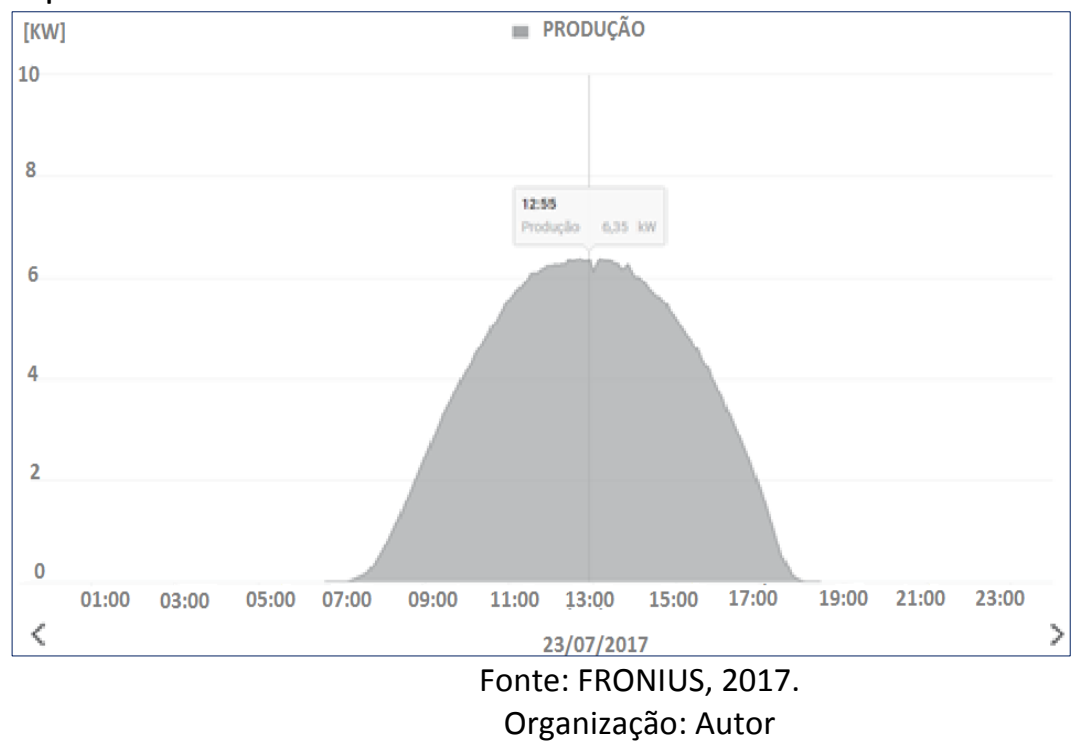

Gráfico 2. Energia entregue pela concessionária, em KWh

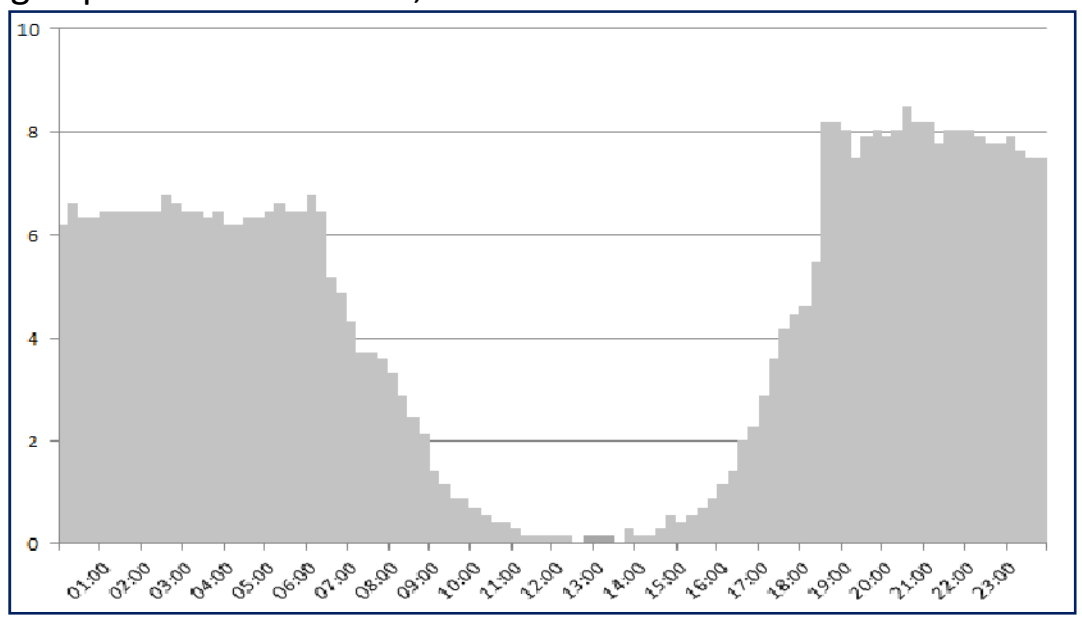

Fonte: ENERGISA, 2017

Organização: Autor 
Gráfico 3. Energia injetada na rede, em KWh.

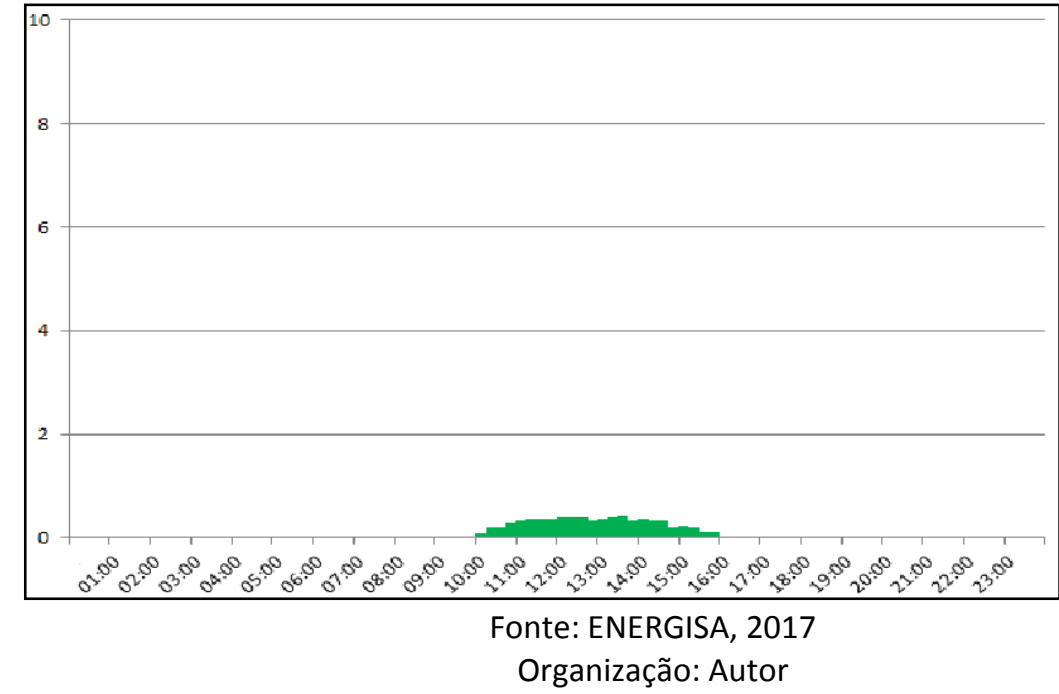

\section{DISCUSSÃO}

Esta análise demonstrou a funcionalidade da micro usina fotovoltaica. É importante salientar que a sua capacidade de geração é bastante pequena em relação ao consumo da instituição (ver Tabela 2), porém, observando o funcionamento nos dias em que há sol pleno e que há baixo consumo, é possível notar que há exportação do excedente de energia gerada para o sistema, confirmando a aplicabilidade da micro usina. De acordo com a resolução 482/2012 revisada pela resolução 687/2015, ambas da Aneel, esta energia excedente não será ressarcida em espécie, porém o valor em $\mathrm{KWh}$ será descontado do consumo registrado pela concessionária. $\mathrm{O}$ prazo para compensação deste excedente é de 60 meses, podendo ocorrer primeiramente no estabelecimento onde a energia foi gerada e, se necessário, em outra UC da qual faça parte. Após este prazo, não há como reaver os valores excedentes gerados pela micro usina.

Apesar de o período analisado ter sido pequeno devido ao fato de a unidade geradora ter iniciado as operações no final do mês de maio de 2017 e os meses possuírem as menores médias diárias de irradiação solar, o objetivo da pesquisa foi atingido ao ser demostrada a viabilidade técnica das instalações.

A micro usina implantada é conectada à rede elétrica que fornece energia para a instituição. Como não há sistema de armazenamento, toda energia gerada e não consumida é exportada para o sistema, que funciona como um armazenador. Esta energia retorna para a unidade consumidora nos horários em que o consumo é maior do que a geração. Este sistema evita investimentos em equipamentos de armazenamento, bem como, despesas com a manutenção destes.

Outro ponto a ser destacado é com relação ao conceito de geração distribuída. As usinas geradoras de energia elétrica implantadas atualmente no Brasil são concebidas como complexos geradores e geralmente estão distantes dos grandes centros de consumo. Além dos elevados investimentos para interligar todo o sistema, segundo dados da EPE (2016), as perdas no Sistema Interligado Nacional são de 20,1\% (vinte inteiros e um décimo por cento).

O sistema permite a inclusão de mais sistemas geradores conectados paralelamente, aumentando a produção de energia elétrica. Para isto se faz necessário um estudo mais detalhado do consumo da unidade por um período mais longo. 


\section{CONCLUSÃO}

Conclui-se que o sistema de cogeração de energia elétrica utilizando a luz solar como fonte é tecnicamente viável e apresenta resultados satisfatórios.

Considerando que, conforme a segunda lei da termodinâmica, na transformação da energia de uma forma para outra, essa sempre caminha da forma mais proveitosa para outra menos proveitosa, ou seja, há uma parcela da energia que desprende para o sistema, conclui-se que a geração de energia elétrica por meio da energia da luz solar é sem dúvida a mais eficiente.

É necessário que haja maiores incentivos na geração de energia elétrica por meio de fontes alternativas, especialmente a Solar. Esta fonte de energia, considerada a menos poluente, contribui tão pouco para a matriz energética brasileira que não aparece nos índices apresentados na Tabela 1.

\section{REFERÊNCIAS}

BRAGA, B. et al. Introdução à engenharia ambiental: o desafio do desenvolvimento sustentável. 2.ed. São Paulo: Prentice Hall, 2007.

BOTKIN, D.B.; KELLER E.A. Ciência ambiental: terra, um planeta vivo, 7.ed. Rio de Janeiro: LTC, 2011.

CARVALHO, J. F. Energia e sociedade. Estud. avançados, São Paulo , v. 28, n. 82, p. 25-39, dez. 2014. Disponível em <http://www.scielo.br/scielo.php?script=sci_arttext\&pid=S0103$40142014000300003 \& \operatorname{lng}=e n \& n r m=i s o>$. Acesso em 08 agosto 2017.

EMPRESA DE PESQUISA ENERGÉTICA - EPE. Anuário estatístico de energia elétrica 2016. Brasília: Ministério de Minas e Energia, $2016 . \quad$ Disponível em <http://www.epe.gov.br/AnuarioEstatisticodeEnergiaEletrica/Forms/Anurio.aspx>. Acesso em 02 novembro 2016.

ENERGISA. Hemera. Disponível em: <https://eletricidade.energisa.com.br/hemera/>. Acesso em 02 agosto 2017.

FEARNSIDE, P. M. Hidrelétricas na Amazônia: impactos ambientais e sociais na tomada de decisões sobre grandes obras. 1.ed. Manaus: editora do INPA, 2015.

FRONIUS. Fronius Solar.web. Disponível em: <https://www.solarweb.com/>. Acesso em 25 julho 2017.

LOPEZ, R. A. Energia Solar para produção de eletricidade. 1.ed. São Paulo: Artibier, 2012.

REIS, L. B. Geração de energia Elétrica: tecnologia, inserção ambiental, planejamento, operação e análise de Viabilidade. 3.ed. Barueri: Manole, 2003.

VIEIRA, S. et al. Uma comparação entre deduções da equação $E=m c^{2}$. Revista Brasileira de Ensino de Física, 26(2), 93-98. 2004. Disponível em: <ttps://dx.doi.org/10.1590/S1806$11172004000200003>$. Acesso em 08 agosto 2017.

ZILLES, R. et al. Sistemas fotovoltaicos conectados à rede elétrica. 1.ed. São Paulo: Oficina de Textos, 2012. 